\title{
Service Quality, Perceived Value, and Fan Engagement: Case of Shanghai Formula One Racing
}

\author{
Charles W. Jones, Kevin K. Byon, and Haiyan Huang
}

Charles W. Jones, $\mathrm{PhD}$, is an assistant professor in the Department of Sport, Exercise, Recreation, and Kinesiology at East Tennessee State University. His research interests include sport marketing and sport consumer behavior, primarily in the context of collegiate athletics and recurring mega sport events.

Kevin K. Byon, PhD, is an associate professor in Department of Kinesiology at Indiana University. His research interests include psychological and environmental variables affecting consumer behavior within sport marketing and sport tourism.

Haiyan Huang, $\mathrm{PhD}$, is a professor in the Shanghai Collaborative Innovation Center of Sports and Health Industry at Shanghai University of Sport. His research interests include event management and sport tourism. He is the corresponing author for this article.

\begin{abstract}
The purpose of this study is to examine the influence of controllable service quality factors as firm-based antecedents to two dimensions of customer engagement behavior among Formula One racing spectators. This study uses the theory of customer engagement (van Doorn et al., 2010) as a guiding framework and applies Bettencourt's (1997) model of customer voluntary performance (CVP) to examine how perceptions of ancillary services and value can prompt management cooperation and prosocial behavior among spectators of a recurring mega sport event. Findings suggest that spectator interactions with event personnel and the physical environment can positively impact consumer perceptions of value and lead to greater fan engagement. Event organizers should focus management and marketing efforts on the utilitarian value (price/value for money) associated with attending a mega event and promote physical environment factors that can enhance the overall event experience.
\end{abstract}

Keywords: fan engagement, service quality, perceived value, Formula One (F-1)

http://doi.org/10.32731/SMQ.282.062019.01

\section{Introduction}

Consumer behavior research has shown that highly engaged customers can benefit organizations by working collaboratively with them to develop or improve product offerings, by providing positive word-ofmouth referrals, and by engaging with other customers through helping behaviors such as sharing product knowledge and information (van Doorn et al., 2010). In sport management, research has shown that sport fans also engage in various ways including behavior that can benefit both the sport organization and other fans (Yoshida, Gordon, Nakazawa, \& Biscaia, 2014). For instance, spectators at live sport events engage socially with other spectators, which can enhance the in-game experience (Westerbeek \& Shilbury, 2003); fans join sport- or team-related member organizations such as fan clubs and alumni associations (Bernthal, Koesters, Ballouli, \& Brown, 2015); and fan groups use formalized communications (i.e., online or in person) to communicate game-day rituals and expectations for spectator conduct (McDonald \& Karg, 2014). This line of research has shown that highly engaged fans are more likely to renew season ticket plans, watch games on TV, recruit other fans, attend future games together, and purchase sport-related merchandise (Bernthal et al., 2015; McDonald \& Karg, 2014; Swanson, Gwinner, Larson, \& Janda, 2003; Yoshida et al., 2014).

The van Doorn et al. (2010) model of customer engagement behavior suggests there are many potential factors that might influence a customer's desire 
to engage including firm-based, customer-based, and context-based variables. For this study, the impact of two controllable service quality factors (firm-based antecedents) - specifically, the quality of spectator interactions with both event personnel and physical environment elements-and its influence on two engagement behaviors (prosocial behavior and management cooperation), as mediated by customer perceptions of utilitarian and hedonic value, is examined. Identifying how controllable service factors can impact customer value and future engagement behavior, and which antecedents are stronger predictorscan not only advance our theoretical understanding of how and why sport fans engage-but through a greater understanding of the different ways that sport organizations can facilitate engagement, managers and marketers can focus their efforts on specific firmbased resources that are likely to increase customer value and prompt future prosocial and management cooperation behavior.

As sport organizations work to expand their fan base, utilizing fans as resources to help grow the sport, recruit new fans, and provide a safe and memorable experience is critical to the organization's success (Jensen, Cobbs, \& Groza, 2014). As van Doorn et al. (2010) asserted-building and sustaining a firm's customer base "may require the firm to look beyond repurchase behavior alone" (p. 253). Facilitating these engagement behaviors can hold even greater importance when introducing a sport product into new markets. Creating long-term sustainable interest and engagement requires managers and marketers to "prioritize and cultivate key resources" (Jensen et al., p. 247). This is especially true for international sport organizations such as Formula One Racing (hereafter F-1), who use a niche portfolio strategy to introduce the sport in new geographic areas. Recent history shows that some F-1 circuits have excelled while other circuits have been dropped from the schedule for reasons including poor attendance and a lack of fan support (BBC Sport, 2011).

As Jensen et al. (2014) asserted, "the effectiveness of a niche marketing strategy is resource dependent" ( $p$. 248). These resources can include organization-related resources (i.e., event personnel and elements related to the sport venue); but just as important are event spectators, whose prosocial and management cooperation behaviors can positively impact the sport experience of other fans, increase fan support of the sport and sport event, and ensure the safety of other spectators. In the context of a global sport such as F-1-and specifically where the sport is a relative newcomer-these relationships become even more important in order to achieve long-term sustainability and profitability of the event.

The Chinese Grand Prix provides an excellent case study to investigate the proposed relationships. As Jensen et al. (2014) noted, there are various types of resources (i.e., participant, media, sponsor, and spectator) that can increase consumer demand for the sport of F-1. However, for countries such as China-who are void of participant resources (i.e., no history of F-1 drivers or teams), which can directly impact demand for the sport-the role and necessity of spectator resources is even greater. Shanghai has hosted the Chinese Grand Prix F-1 racing event since 2004, and while some studies suggest the F-1 event has had a positive economic impact on the Shanghai region (Huang, Mao, Kim, \& Zhang, 2014; Ma, Huang, \& Huang, 2011), attendance at the Chinese GP has declined from a peak of 270,000 in 2005 to approximately 160,000 spectators attending the three-day event in 2016. Furthermore, television viewing of the Chinese GP declined from 30 million to 19 million viewers in 2013 following a broadcasting change from state broadcaster CCTV to regional outlets (Johnson, 2016). This decline in attendance and TV viewership suggests that event organizers must find ways to increase interest in the event and develop new F-1 racing fans in order to secure the Chinese Grand Prix's future viability. Finding ways to facilitate fan engagement behavior among current F-1 racing fans and spectators of the Chinese GP is a strategic way for event organizers to increase interest in both the sport of F-1 racing and the Chinese GP event.

There are three primary areas of focus in this study. First, this study examines the influence of controllable service elements on customer perceived value and two non-transactional extra-role engagement behaviors. Second, this study examines which service elements are stronger or weaker predictors of prosocial and management cooperation behavior, as mediated by customer perceived utilitarian and hedonic value. Third, this study looks at these relationships in the context of the F-1 Chinese Grand Prix-a sport event that has experienced declining attendance and fan interest since its inaugural running in 2004. Thus, the objectives for this study are the following: a) use van Doorn et al.'s (2010) theory of customer engagement as a guiding framework to examine firm-based and customer-based antecedents to two dimensions of customer engagement; b) identify which controllable service elements (service variables associated with event personnel and with the physical environment) are stronger or weaker predictors of spectator 
prosocial and management cooperation behavior; and c) use the F-1 Chinese Grand Prix as a meaningful case study to examine the proposed relationships.

\section{Theoretical Framework}

\section{Interaction and Physical Environment Service Quality}

Empirical research in sport has demonstrated the importance of service quality on the overall customer experience (e.g., Byon, Zhang, \& Baker, 2013). In spectator sport, the sport product is often viewed as two distinct service categories: the core service product and the ancillary service product (Byon et al., 2013). Core service refers to the sport event itself-for instance, factors related to the game, team, or players, while ancillary service refers to peripheral elements such as the helpfulness or professionalism of event staff, accessibility in and around the venue, and the quality of food and other amenities.

Brady and Cronin (2001) introduced a service quality model that separated ancillary service quality elements into two dimensions: one based on human interactions (service quality evaluations based on interactions with event staff) and one based on interactions with the physical environment (service quality evaluations of the physical environment). While core service quality has been found to influence behavioral intentions (e.g., Byon et al., 2013), marketers have no control or influence over game or competition outcomes. However, managing the quality of ancillary elements is a primary function of the event management team and how well these services are provided can impact the consumption levels of event spectators (Byon et al., 2013).

Following the Brady and Cronin (2001) model, and focusing on controllable service quality elements, this study examined ancillary service quality as two distinct constructs. Interaction service quality focuses on the courtesy and professionalism of event personnel, including ticket takers, security officers, ushers, and restaurant servers, while physical environment quality focuses on elements related to the sport facility including venue aesthetics, layout, accessibility, signage, seating comfort, scoreboard quality, and the quality of concessions offered. From a practitioner's perspective, focusing on controllable service factors and how they can impact perceived value and fan engagement behavior can provide meaningful implications for marketers and managers of sport organizations.

\section{Utilitarian and Hedonic Value}

The consumption of sport through live game attendance is a leisure activity that can produce both hedonic and utilitarian value for game spectators (Yoshida, James, \& Cronin, 2013). Live sporting events are inherently a hedonic and experiential product. For example, after attending a game, spectators may express how exciting the game was or the waves of emotion they experienced during the sporting event. There is also utilitarian value that spectators assign to game consumption based on an evaluative judgment concerning the costs associated with attending (money and time) compared to the benefits received (Byon et al., 2013). For instance, customers often consider if they got their money's worth based on the overall experience of attending the event.

As Babin, Darden, and Griffin (1994) and other scholars have suggested (e.g., Byon et al., 2013; Petrick, 2002; Sweeney \& Soutar, 2001), how value is conceptualized and measured empirically should depend on a study's context. Babin et al. (1994) demonstrated the importance of context in their validation of a personal shopping value scale by identifying that mall shoppers assign value to both the functional aspect (locating and purchasing items) and the hedonic aspect (joy and excitement) of the overall shopping mall experience. The spectator sport experience shares many of these same attributes and a similar approach to conceptualizing perceived value can be applied.

Following Babin et al.'s (1994) study, researchers have developed and tested multi-dimensional scales for measuring perceived value that contained both hedonic and utilitarian components (e.g., Petrick, 2002; Sweeney \& Soutar, 2001). Sweeney and Soutar introduced the PERVAL scale and through their research, found that consumers perceive value based on different factors including the emotional and utilitarian value (e.g., price/value for money) generated by a product. Petrick (2002) introduced the SERV-PERVAL scale and also found that consumers perceive value based on emotional (e.g., feelings of pleasure) and utilitarian (e.g., monetary price) components.

For the current study, perceived value was examined as a two-dimensional construct where hedonic and utilitarian value assessments were considered. Babin et al. (1994) referred to this as an "experiential perspective" where both the merit of the consumption experience and the emotional costs and benefits are examined to better understand the consumption activity. Here, both the hedonic (emotion-driven value) and utilitarian value (price/value for money) associated with the live sport experience were measured and their role as intermediary variables between interaction and physical environment elements and prosocial and management cooperation behavior were examined. 


\section{Management Cooperation and Prosocial Behavior}

Successful organizations understand that customers are a valuable asset to their firm and managing customer relationships must always be a top priority (Verhoef, Reinartz, \& Krafft, 2010). Indeed, prioritizing and cultivating customers as key resources of the organization can help firms penetrate new markets and achieve sustained profitability (Jensen et al., 2014). While customer management research has mainly focused on the transactional side of these relationships, studies examining customer engagement through non-transactional extra-role behaviors have recently received more attention in management and marketing literature (Brodie, Hollebeek, Jurić, \& Ilić, 2011; Kumar et al., 2010; Verhoef et al., 2010). As societies become more networked through social and other media, the study and understanding of consumers' extra-role behaviors is becoming more important to both academics and practitioners. For businesses and organizations, ignoring extra-role behaviors such as customer-to-customer interactions (e.g., word-ofmouth) or management cooperation behaviors (e.g., the co-creation of products and services) can lead to lost revenue and missed growth opportunities (Kumar et al., 2010; Verhoef et al., 2010).

In the business literature, van Doorn et al. (2010) approached customer engagement from a behavioral perspective, suggesting that customer engagement behaviors go beyond the purchase transaction. van Doorn et al. (2010) defined customer engagement as "a customer's behavioral manifestations that have a brand or firm focus, beyond purchase, resulting from motivational drivers" (p. 254). Customer engagement behaviors may be targeted not just towards an organization's employees, but also towards its current as well as potential customers (Kumar et al., 2010; van Doorn et al., 2010). These behaviors can include promoting the organization's products or services or helping to improve the experiences of other customers, each of which are considered aspects of value co-creation (Brodie et al., 2011; Kumar et al., 2010; van Doorn et al., 2010).

Fan engagement can be viewed as a specific form of customer engagement in the context of sport (Yoshida et al., 2014). Yoshida et al. reviewed fan engagement studies in the sport marketing literature and found that in addition to performing "self-interested" behaviors (e.g., attending sport events, consuming through media, purchasing team-related merchandise), highly engaged fans also perform many extra-role behaviors, including supportive word-of-mouth communication, social interaction, sharing knowledge of the game or team, and other displays of sport fandom. More recent studies have shown that fans also engage by joining sport- or team-related member organizations (e.g., fan clubs and alumni associations: Bernthal et al., 2015) and using social media platforms and applications to connect with other fans and share team information (Gibbs, O'Reilly, \& Brunette, 2014; Watkins \& Lewis, 2014).

Bettencourt (1997) described customers who engage in these ways as partners in service delivery who perform helpful, discretionary behaviors "that support the ability of the firm to deliver service quality" (p. 384). These behaviors include loyalty and cooperation behaviors such as speaking positively of the organization, working cooperatively with the organization, and sharing product knowledge with other customers. Based on these precepts, Bettencourt conceptualized a model of customer voluntary performance (CVP) where the customer is viewed as both an important promoter of and a human resource for the organization.

In this regard, prosocial behavior and management cooperation are two specific types of fan engagement behavior that can benefit both the sport organization and other fans. In the context of this study, prosocial behavior refers to "fan-to-fan helping behaviors" where fans share knowledge of the sport, team, and event with other fans through direct interactions at the event or through digital media platforms (Yoshida et al., 2014, p. 404). In this role, fans act as advocates for the sport and the organization. Management cooperation refers to spectator behavior that supports the functions and goals of management (Auh, Bell, McLeod, \& Shih, 2007; Bettencourt, 1997; Yoshida et al., 2014). Building on the work of Auh et al. (2007) and Bettencourt (1997), Yoshida et al. (2014) defined management cooperation as "a sport consumer's collaborative, constructive participation in the value creation and service delivery process at sporting events" (p. 404). In the context of live sport events, this includes adhering to ethical codes of conduct and working cooperatively with event personnel to ensure the safety of other spectators (Auh et al., 2007; Bettencourt, 1997; Yoshida et al., 2014). At a time where organizations and fans have a heightened awareness for safety and security concerns-particularly where large masses of people are gathered-cooperation with management and adherence to ethical rules of conduct is a critical factor for ensuring a safe and memorable spectator experience.

For recurring mega sport events such as the international circuits of F-1 racing, management cooperation and prosocial behaviors performed by F-1 spectators can produce benefits for all event stakeholders. For 
example, individuals who assist management personnel or share their knowledge of the sport with other fans (both at the venue and through social media) can improve management effectiveness of the event, bolster the experience of other fans, and help to grow the reach of the sport-all of which can lead to increased fan identification with the sport, higher future attendance, and greater revenues for event organizers and the F-1 organizing body.

\section{Hypothesis Development}

The van Doorn et al. (2010) model of customer engagement behavior suggests there are many potential factors that might influence a customer's desire to engage, including customer-based (i.e., positive affect, brand commitment, perceived costs/benefits, and brand performance perceptions), firm-based (i.e., perceived characteristics of the brand), and context-based (i.e., economic, environmental, and social factors) variables. The scholars postulate that these different antecedent variables can affect customer engagement behavior directly, or indirectly, as "these factors can interact with each other and help enhance or inhibit the effect of a particular focal factor on CEB" (p. 256).

In the study presented here, we investigated both firm-related (i.e., interaction and physical environment service quality factors) and customer-related (i.e., utilitarian and hedonic value perceptions) antecedents to fan engagement behavior and tested their influence on the management cooperation and prosocial behavior of sport spectators. As van Doorn et al. (2010) asserted, investigating specific antecedents to different types of customer engagement-and identifying which antecedents are stronger or weaker predictors of future engagement behavior-can contribute meaningful theoretical and practical implications.

Prior research confirms the quality-value-behavior relationships that can exist in different settings (Byon et al., 2013; Cronin, Brady, \& Hult, 2000; Yoshida et al., 2013). However, as of this date, no prior studies have investigated the specific effects of controllable service quality factors (i.e., interaction and physical environment quality) on a sport fans' propensity to engage as both a human resource (i.e., through management cooperation) and as a promoter of the firm (i.e., through prosocial behavior). It can be theorized that based on the transactional nature of the interaction service quality and utilitarian value constructs, the association between these two factors will be stronger than the association between interaction service quality and hedonic value. Furthermore, if we consider prior research (e.g., Wakefield, Blodgett, \& Sloan, 1996) that confirmed certain physical environment variables can have a positive influence on the pleasure experienced by sport spectators, it can be theorized that physical environment quality will have a stronger association with hedonic value than with the utilitarian value experienced by event attendees.

To theorize the expected relationships between the two value dimensions and the two extra-role behaviors, it may be worthwhile to consider how each variable was measured. Utilitarian value was measured as the perceived price/value for money spent. It can be expected that when greater perceptions of utilitarian value are experienced, spectators may feel more inclined to do things to make the event's management easier. As well, hedonic value was measured as emotion-driven value based on the thrill and excitement of the event. It can be expected that when greater levels of hedonic value are experienced, spectators may be eager and willing to share information about the event or the sport with other fans. Thus, the following hypotheses are proposed:

H1a: Interaction service quality will have a stronger association with utilitarian value than hedonic value

H1b: Physical environment service quality will have a stronger association with hedonic value than utilitarian value

$\mathrm{H} 2 \mathrm{a}$ : Utilitarian value will have a stronger association with management cooperation than prosocial behavior

H2b: Hedonic value will have a stronger association with prosocial behavior than management cooperation

\section{Method}

\section{Participants and Data Collection Procedures}

Spectators attending the Chinese Grand Prix race on the final day of the three-day F-1 event were recruited for this study. In order to control for the influence of core-service related variables, data were collected prior to the start of the final race. Although random sampling is a preferred method, collecting data randomly was not feasible due to the size and scale of the event. Thus, a convenience sample was obtained using the following data collection procedures: (a) 15 trained assistants were stationed in all three seating sections (i.e., main straight, back straight, and general admission). This ensured a representative sample reflective of spectators seated in the different sections; (b) data were only collected from spectators who also attended at least one of the practice or qualifying sessions (i.e., practice round held in day 1 or qualifying round held in day 2). This requirement was to increase opportunities for study participants to experience service encounters with event staff and increased interaction with physical environment variables; and (c) incentives 
(e.g., Shanghai F-1 souvenir) were provided in return for participating in the survey.

As a result of these data collection practices, data were collected from 655 spectators who attended both the final day of the F-1 event and at least one of the practice or qualifying sessions. Eighteen questionnaires were found to be incomplete for a total of 637 responses $(N=637)$. The research participants skewed towards being male where men accounted for $64.6 \%$ and women accounted for $35.4 \%$ of total respondents. Approximately $70 \%$ of respondents were 36 years of age or younger and approximately $80 \%$ were 42 years of age or younger.

\section{Measures}

The instrument for this study consisted of four sections: a) service quality; b) perceived value; c) fan engagement behavior; and d) socio-demographic and attendance information. Scale items were modified from pre-existing scales (e.g., Byon et al., 2013; Dholakia, Blazevic, Wiertz, \& Algesheimer, 2009; Hill \& Green, 2000) to fit the context of this study.

Guided by the Brady and Cronin (2001) model, controllable service quality elements were measured based on the following two dimensions: interaction quality (human elements) and physical environment quality (nonhuman elements). As Brady and Cronin (2001) confirmed, the interaction service quality perceived by customers can be influenced by the attitude, behavior, and expertise of the organization's employees (i.e., the friendliness, courtesy, and professionalism exhibited). For this study, specific personnel were selected with whom a spectator would most likely have interactions with during the event (i.e., ticket takers, security officers, ushers, and restaurant workers) and the friendliness, courtesy, and professionalism experienced during these interactions was measured using six items adapted from previous scales (Byon et al., 2013). Physical environment quality was assessed by measuring environmental elements often found in the sportscape, including venue aesthetics, layout, accessibility, signage, seating comfort, scoreboard quality, and the quality of concessions offered. Six items adapted from previous scales (Hill \& Green, 2000; Wakefield et al., 1996) were used to measure this construct.

Perceived value was measured based on two dimensions: utilitarian value and hedonic value. Utilitarian value (price/value for money) was assessed using three items (Byon et al., 2013) and hedonic value (emotion-driven value) was assessed via four emotional response items (i.e., "Happy", "Energetic", "Excited", and "Thrilled") precluded by the phrase, "At the F-1 event I feel..." (Petrick, 2002).
To investigate the spectator's role as both a human resource of and a promotor for the organization, two extra-role fan engagement behaviors were measured. Management cooperation (Auh et al., 2007; Bettencourt, 1997; Yoshida et al., 2014) and prosocial behavior (Dholakia et al., 2009; Yoshida et al., 2014) were each measured using three items adapted from previous research. A 7-point Likert scale anchored by "strongly disagree" (1) and "strongly agree" (7) was used to measure all the constructs within the proposed model. The final section contained questions phrased in a multiple-choice format to measure demographic information including gender, age, ethnicity, education, and place of residence. All measurement items are presented in the Appendix.

It is important to consider fan composition at Formula One events where spectators are comprised of multiple nationalities. According to Sylt and Reid (2011), on average, $20-30 \%$ of spectators attending F-1 events are international traveling fans. As such, surveying diverse fans-including foreign nationalsis essential to accurately represent the composition of fans attending an F-1 event. Thus, two types of survey questionnaires were formed: (a) a Chinese version and (b) an English version. Accordingly, a back translation was conducted to ensure translation accuracy (Brislin, 1970). First, the original scales were translated into Chinese by a native Chinese who was fluent in English. Then, the translated version was converted back into English by a scholar who was also fluent in both English and Chinese. Following the back translation, it was found that there were no discrepancies in terms of the clarity of the items between the two versions.

\section{Results}

\section{Measurement Model}

Anderson and Gerbing's (1988) two-step modeling approach was then used to test the hypothesized structural model. A confirmatory factor analysis (CFA) was first performed to test the measurement model, followed by a structural equation modeling (SEM) to test the hypothesized structural model using the MPlus 6 statistical modeling program. A CFA was performed and results provided support for the measurement model. Per Hair et al.'s (2010) recommendation for examining model fit, several goodness of fit measures were adopted and results showed that the data fit the model well $\left(X^{2}=930.94, p<.001 ; X^{2} / \mathrm{df}=3.58\right.$; CFI $=$ 0.94 ; RMSEA $=0.06$; and SRMR $=0.04$ ).

All factor loadings were statistically significant $(p<$ .05 ) and ranged from 0.61-0.91, demonstrating good convergent validity (Anderson \& Gerbing, 1988). Discriminant validity was confirmed using Fornell 
and Larcker's (1981) criterion where the squared correlations between all latent variables were compared to their respective AVE values. None of the squared correlations were above their respective AVE values, providing support for discriminant validity. Reliability was assessed through the evaluation of Cronbach's alpha, composite reliability (CR), and average variance extracted (AVE). All values were above the respective thresholds (i.e., 0.70, 0.70, and 0.50: Bagozzi \& Yi, 1988; Fornell \& Larcker, 1981; Hair et al., 2010) with the exception of one factor (physical environment quality) whose AVE value was slightly below the cutoff $(\mathrm{AVE}=0.45 ; \mathrm{CR}=0.83)$. Factor loadings and reliability scores are presented in Table 1.

\section{Model Comparison}

Before proceeding to analyzing the proposed model, the hypothesized structural model was compared to a more restricted model using the $\mathcal{X}^{2}$ difference test (Kline, 2010). For the competing model, four paths were hypothesized to represent sequential relationships between constructs (i.e., interaction quality - utilitarian value - management cooperation

Table 1. Results of Confirmatory Factor Analysis $(N=637)$

\begin{tabular}{|c|c|c|c|c|}
\hline Variables & $\lambda$ & $\alpha$ & CR & AVE \\
\hline Interaction Service Quality (ISQ) & & .94 & .95 & .74 \\
\hline ISQ 1 & .89 & & & \\
\hline ISQ 2 & .91 & & & \\
\hline ISQ 3 & .91 & & & \\
\hline ISQ 4 & .80 & & & \\
\hline ISQ 5 & .84 & & & \\
\hline ISQ 6 & .82 & & & \\
\hline Physical Environment Quality (PEQ) & & .83 & .83 & .45 \\
\hline PEQ 1 & .61 & & & \\
\hline PEQ 2 & .73 & & & \\
\hline PEQ 3 & .72 & & & \\
\hline PEQ 4 & .69 & & & \\
\hline PEQ 5 & .67 & & & \\
\hline PEQ 6 & .61 & & & \\
\hline Utilitarian Perceived Value (UPV) & & .90 & .90 & .75 \\
\hline UPV 1 & .87 & & & \\
\hline UPV 2 & .89 & & & \\
\hline UPV 3 & .84 & & & \\
\hline Hedonic Perceived Value (HPV) & & .93 & .94 & .78 \\
\hline HPV 1 & .84 & & & \\
\hline HPV 2 & .89 & & & \\
\hline HPV 3 & .91 & & & \\
\hline HPV 4 & .90 & & & \\
\hline Management Cooperation (MGC) & & .90 & .90 & .76 \\
\hline MGC 1 & .89 & & & \\
\hline MGC 2 & .88 & & & \\
\hline MGC 3 & .82 & & & \\
\hline Prosocial Behavior (PSB) & & .94 & .94 & .83 \\
\hline PSB 1 & .88 & & & \\
\hline PSB 2 & .85 & & & \\
\hline PSB 3 & .74 & & & \\
\hline
\end{tabular}


and physical environment quality - hedonic value - prosocial behavior). The more restricted model was proposed based on results of prior studies that show interaction quality elements can be positively associated with utilitarian value (Yoshida et al., 2013), while physical environment variables can prompt the hedonic feelings spectators often experience in a sport setting (Wakefield et al., 1996).

SEM was performed on the competing model and multiple goodness-of-fit measures were computed $\left(X^{2}\right.$ $=1239.00, p<.001 ; \chi^{2} / \mathrm{df}=4.61 ; \mathrm{CFI}=0.92 ;$ RMSEA $=$ 0.08 ; and SRMR $=0.14$ ). To perform the $\mathcal{X}^{2}$ difference test, the difference in $X^{2}$ values and degrees of freedom was calculated $\left(\Delta X^{2}{ }_{(4)}=198.60\right)$ and the result indicated that the $X^{2}$ difference was found to be statistically significant $\left(\Delta \mathcal{X}_{(4)}^{2}=198.60\right)$ at the .01 level, indicating that the proposed model is deemed superior.

\section{Common Method Variance}

Examining the common method variance (CMV) was necessary to confirm whether the results of the current study were biased by CMV, which is defined as "variance that is attributable to the measurement method rather than to the constructs the measures represent" (Podsakoff, MacKenzie, Lee, \& Podsakoff, 2003, p. 879). Testing for CMV was crucial because the findings were derived from data that were collected from the same source (e.g., spectator), and predictors and outcome variables were measured simultaneously. To this end, we conducted an ex-post statistical control in dealing with CMV bias: Harman's single factor method (Andersson \& Bateman, 1997). In terms of the Harman's single factor method, this technique has been regarded as one of the most widely used methods to examine CMV (Podsakoff et al., 2003). In order to run this test, we loaded all variables used in the model into exploratory factor analysis (EFA) using principal component analysis (PCA) with unrotated factor solution. The results showed that a total of $27 \%$ of the variance was explained by the single factor. Scholars suggest that if a total variance explained is less than $50 \%, \mathrm{CMV}$ is not an issue (Andersson \& Bateman, 1997; Aulakh \& Gencturk, 2000).

\section{Structural Model}

An SEM was performed to examine path coefficients and strength of associations among the six factors. Goodness-of-fit measures showed that the data for the proposed structural model fit the model well $\left(X^{2}=\right.$ $1040.40, p<.001 ; \chi^{2} / \mathrm{df}=3.92 ; \mathrm{CFI}=0.94$; $\mathrm{RMSEA}=$ 0.07 ; and SRMR $=0.07$ ). Hypothesis 1a predicted that interaction quality would have a stronger association with utilitarian value than with hedonic value. While both relationships were positive and statistically significant, interaction quality had a slightly stronger association with hedonic value $(\beta=0.34, p<.001)$ than with utilitarian value $(\beta=0.32, p<.001)$, thus Hypothesis la was not supported. Hypothesis $1 \mathrm{~b}$ predicted that physical environment quality would have a stronger association with hedonic value than with utilitarian value. However, although both relationships were positive and statistically significant, physical environment quality had a stronger association with utilitarian value $(\beta=0.44, p<.001)$ than with hedonic value $(\beta=0.21, p<.001)$, thus Hypothesis $1 \mathrm{~b}$ was not supported.

Results also indicated that utilitarian value had a stronger association with management cooperation $(\beta=0.41, p<.001)$ than with prosocial behavior $(\beta$ $=0.35, p<.001)$, thus Hypothesis $2 \mathrm{a}$ was supported.

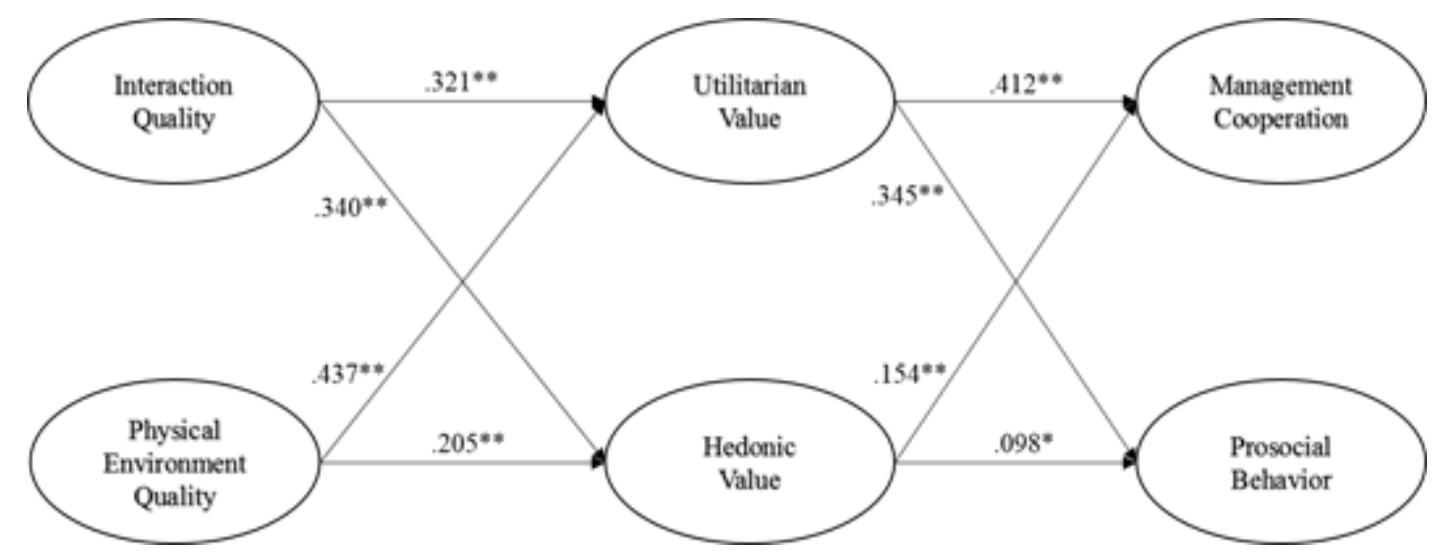

Figure 1. Final research model

Goodness-of-fit statistics:

$X^{2}=1040.40 ; \mathrm{CFI}=.94 ; \mathrm{RMSEA}=.07$; $\mathrm{SRMR}=.07$

${ }^{\star} p<.05,{ }^{* *} p<.01$ 
Table 2. Mediation of the Effects of Interaction and Physical Environment Service Quality on Management Cooperation and Prosocial Behavior through Utilitarian and Hedonic Value

\begin{tabular}{|c|c|c|c|c|c|c|}
\hline \multirow[b]{2}{*}{ Path/effect } & \multicolumn{2}{|c|}{ SEM Result } & \multicolumn{2}{|c|}{ Bootstrap Estimate } & \multicolumn{2}{|c|}{ Bootstrap Percentile $(95 \% \mathrm{CI})$} \\
\hline & $\beta$ & SE & $\beta$ & SE & Lower & Upper \\
\hline Interaction SQ $\rightarrow$ Utilitarian Value & $0.321^{\star *}$ & 0.046 & $0.346^{* *}$ & 0.071 & 0.220 & 0.460 \\
\hline Utilitarian Value $\rightarrow$ Management Cooperation & $0.412^{* *}$ & 0.042 & $0.423^{* *}$ & 0.055 & 0.334 & 0.512 \\
\hline Interaction SQ $\rightarrow$ Hedonic Value & $0.340^{* *}$ & 0.051 & $0.328^{* *}$ & 0.065 & 0.220 & 0.437 \\
\hline Physical Environment SQ $\rightarrow$ Utilitarian Value & $0.437^{\star *}$ & 0.048 & $0.656^{* *}$ & 0.092 & 0.511 & 0.812 \\
\hline Utilitarian Value $\rightarrow$ Prosocial Behavior & $0.345^{\star *}$ & 0.046 & $0.360^{* *}$ & 0.060 & 0.264 & 0.461 \\
\hline Physical Environment SQ $\rightarrow$ Hedonic Value & $0.205^{\star \star}$ & 0.054 & $0.276^{\star *}$ & 0.092 & 0.129 & 0.432 \\
\hline PESQ $\rightarrow$ UV $\rightarrow$ Management Cooperation & $0.180^{* *}$ & 0.028 & $0.278^{* *}$ & 0.056 & 0.195 & 0.378 \\
\hline PESQ $\rightarrow$ HV $\rightarrow$ Management Cooperation & $0.032^{*}$ & 0.012 & 0.049 & 0.026 & 0.016 & 0.098 \\
\hline ISQ $\rightarrow$ UV $\rightarrow$ Prosocial Behavior & $0.111^{* *}$ & 0.022 & $0.125^{* *}$ & 0.031 & 0.073 & 0.176 \\
\hline ISQ $\rightarrow$ HV $\rightarrow$ Prosocial Behavior & $0.033^{*}$ & 0.017 & 0.038 & 0.022 & 0.004 & 0.073 \\
\hline PESQ $\rightarrow$ UV $\rightarrow$ Prosocial Behavior & $0.151^{* *}$ & 0.027 & $0.236^{* *}$ & 0.055 & 0.156 & 0.336 \\
\hline PESQ $\rightarrow$ HV $\rightarrow$ Prosocial Behavior & 0.020 & 0.011 & 0.032 & 0.024 & 0.002 & 0.076 \\
\hline
\end{tabular}

Note. 2,000 bootstrap samples; ${ }^{\star} p<.05,{ }^{* *} p<.01$.

SQ = Service Quality; ISQ = Interaction Service Quality; PESQ = Physical Environment Service Quality; UV = Utilitarian Value; HV = Hedonic Value

Hypothesis $2 \mathrm{~b}$ predicted that hedonic value would have a stronger association prosocial behavior than with management cooperation. However, although both relationships were positive and statistically significant, hedonic value had a stronger association with management cooperation $(\beta=0.15, p<.001)$ than with prosocial behavior $(\beta=0.10, p<.005)$, thus Hypothesis $2 \mathrm{~b}$ was not supported.

\section{Indirect Effects}

To examine these relationships further, the indirect effects of both service quality factors on both fan engagement behaviors as mediated by utilitarian and hedonic value were calculated using bootstrap analysis via the MPlus 6 statistical program. For the analysis, 2,000 bootstrap samples were requested and 95\% confidence intervals were computed using the bootstrap percentile method (Mallinckrodt, Abraham, Meifen, \& Russell, 2006). Results of the analysis are shown in Table 2, including the lower and upper limits for the bootstrap 95\% confidence interval. The confidence intervals for each of the indirect effects do not contain zero; thus, the mediation effect of interaction quality on management cooperation and prosocial behavior through utilitarian and hedonic value, and the mediation effect of physical environment quality on management cooperation and prosocial behavior through utilitarian and hedonic value were statistically significant at the 0.05 level. A total of $47 \%$ of the variance in utilitarian value and $25 \%$ of the variance in hedonic value was explained by interaction quality and physical environment quality factors, while a total of $24 \%$ of the variance in management cooperation and $15 \%$ of the variance in prosocial behavior was explained by perceived utilitarian and hedonic value.

\section{Discussion}

The primary objective of this study was to identify which controllable service elements (service variables associated with event personnel and with the physical environment) had a stronger influence on F-1 spectators' utilitarian and hedonic value perceptions and were stronger or weaker predictors of prosocial and management cooperation behavior. In the conceptual model presented here, ancillary service quality was measured as a two-dimensional construct consisting 
of interaction (human elements) and physical environment (nonhuman elements) factors (Brady \& Cronin, 2001). Perceived value was examined as a two-dimensional construct where an individual's utilitarian and hedonic value perceptions were measured and their role as intermediary variables in the relationship between ancillary service quality and fan engagement behavior was empirically tested. Findings suggest that variables related to the physical environment can have a stronger influence on utilitarian value perceptions and that greater levels of utilitarian value can prompt prosocial and management cooperation behavior.

\section{Theoretical Implications}

This study advances the theory of customer engagement in a sporting context. As van Doorn et al. (2010) conceptualized, both firm-based (interaction and physical environment variables) and customer-based (utilitarian and hedonic value) factors were found to be potential antecedents for greater customer engagement in the F-1 Chinese GP setting. As stated, spectator interactions with human and nonhuman service quality elements were positively associated with both utilitarian and hedonic value. However, while these interactions positively influenced the value spectators associated with the event, the influence of utilitarian value (price/value for money) on management cooperation and prosocial behavior was found to be stronger than the influence of hedonic value on both engagement behaviors. This finding was unexpected and may be somewhat surprising considering the size and spectacle of an F-1 racing event and the hedonic nature of live sport events (Yoshida et al., 2013). However, there are a few possible explanations for why utilitarian value was a stronger predictor of fan engagement.

First, the sport of F-1 is relatively new to China, which poses several challenges. For instance, there are no drivers of Chinese descent driving in the F-1 series. Part of the sport's appeal in many countries is the nationalism associated with supporting a driver from a home country. However, China has no history of F-1 drivers or teams. In addition, the rules of F-1 can be hard to follow, especially for newer fans. As former McLaren team principal Martin Whitmarsh told the Associated Press, "F-1 improves with knowledge... [and] requires an understanding of the latest technology and often the arcane rules that can decide a race" (Casey, 2013). This might suggest that, before fans can appreciate the hedonic aspects associated with attending an F-1 event, they need time to better understand the sport, its cutting edge technology, and its rules. The high cost of attending an international mega sporting event (e.g., ticket purchase, travel, and lodging) should also be considered when interpreting these findings. In fact, event organizers of the Chinese GP have lowered ticket prices in the past to increase affordability for its younger fans (Jensen et al., 2014). Although mega sport events can produce hedonic feelings and great emotion, these results suggest a boundary condition may be present, where the influence of hedonic value on specific engagement behaviors can depend on the price or size of the event.

Findings also show that physical environment variables were a stronger influence on utilitarian value than interaction service quality variables. This may suggest that even though interactions spectators have with event personnel can positively influence utilitarian value perceptions, physical environment factors such as venue aesthetics, layout and accessibility, comfortable seating, and quality of concessions may be more important in impacting how spectators assign value to their overall event experience. Perhaps this is because customers may have consistent expectations when it comes to the service they receive from an organization's employees. However, variables related to the physical environment are one way sport organizations can differentiate themselves and also provide added value to the event experience. Thus, this finding suggests that physical environment variables may be valued more highly (e.g., price/value for money) than spectator interactions with event personnel, especially where the venue and physical surroundings associated with F-1 circuits are typically more glamourous than those venues hosting local events.

The conceptual model presented here was tested in the context of a recurring mega sport event. Results from SEM show that spectators can act as both a human resource and a promotor of the sport organization. Findings suggest that human and nonhuman elements of service quality can positively influence spectator perceptions of utilitarian and hedonic value. Findings indicate that when value perceptions are high, spectators are more likely to interact with other fans to promote the sport and sporting event, and to work cooperatively with event staff to make the event's management easier.

\section{Practical Implications}

Findings from this study also offer important implications for event organizers and marketers of recurring mega sport events such as the Chinese GP. The consumption of sport through live game attendance can produce both hedonic and utilitarian value (Yoshida et al., 2013), and, as these results suggest, spectator interactions with event personnel and physical environment variables can directly impact value perceptions. For large scale events such as those found in F-1 racing-where spectators invest more money (i.e., cost 
of tickets and travel) and time (i.e., travel and duration of the event) than when attending smaller scale sporting events-how well the sport organization delivers ancillary services can directly influence the value spectators associate with the overall event experience.

This includes providing courteous, friendly, and professional services; providing a clean and aesthetically pleasing venue; providing clear directions in and around the venue; providing high quality scoreboards; and providing high quality concessions. In this study, these items were found to directly influence the value spectators associated with attending the mega event. Due to the size and spectacle of mega sport events, and the costs associated with attending them, customers may have higher expectations for these services and how well they are delivered can directly impact value perceptions. While event organizers understand the importance of providing high quality, ancillary services, for recurring mega sport events that only take place once per year, exceeding customer expectations for service quality is crucial for future sustainability of the event.

This study also suggests that the more utilitarian value (price/value for money) spectators associate with attending the event, the more likely they are to engage with event staff and other fans. Findings indicate that managers and event organizers should ensure the costs associated with attending the event (e.g., ticketing, parking, and concessions) are fair and reasonable and that tiered pricing options are available. Organizers of mega sport events should also work with sponsors and partners to minimize gouging and increase the value for other ancillary services (e.g., lodging and travel) associated with attending an international mega sport event. As previously noted, event organizers have worked with F-1 management to provide more affordable ticketing options for event spectators. A further suggestion is to offer a loyalty program that rewards repeat spectators to the Chinese GP event. The findings presented here suggest that the spectators in this market may be more sensitive to pricing, but also more likely to engage with the organization and other fans when value perceptions are higher. Furthermore, as it has been suggested, F-1 is more complicated than other motorsports and it takes time for new fans to understand its rules and intricacies. A loyalty program that provides benefits for repeat attendance can also include a knowledge-based component (i.e., a DVD or book giveaway) to help promote the history and rules of the sport.

The results from this study also suggest that F-1 marketers should emphasize the connection found between physical environment variables and perceptions of utilitarian value. For instance, the Shanghai International Circuit is known for its stunning architecture and Chinese historical elements that are found throughout the venue. Findings suggest that the appealing design of the racing circuit can lead to greater perceptions of value and can prompt prosocial and management cooperation behavior. One suggestion is to provide guided or self-guided tours so spectators can explore all the elements within the venue and gain a better understanding of the historical components that make up the venue's design. The self-guided tours can take place anytime at the spectator's convenience, but guided tours can be offered during the practice and qualifying days or prior to the final race starting on the last day of race weekend. This strategy encourages spectators to visit the venue on days other than the final day, or if they prefer to do the guided tour on the final race session, this offering will require them to arrive early, which is always a challenging objective for event organizers.

Presently, the Chinese GP allows patrons who attend the Friday session to sit anywhere in the grandstands to watch the practice sessions from different views. An additional suggestion is to create a social media campaign using the Sina Weibo (China's version of Twitter as access to Twitter is currently blocked in China) platform, where spectators upload pictures from different views using a specific hashtag. Spectators can be challenged to visit as many different sections as they can and the individual who uploads pictures from the most sections can be selected to win a prize, such as upgraded tickets, a behind-the-scenes tour, or the chance to meet some F-1 drivers. These types of activities can increase engagement that benefits both the spectator and the sport organization.

\section{Limitations and Future Directions}

There are some limitations to this study that should be acknowledged. As noted in the methodology section, data were collected prior to the start of the main race to control for the influence of core service quality variables on perceived value and levels of fan engagement. However, there are other potential determinants of fan engagement behavior that were not controlled for in this study. For instance, Yoshida et al. (2014) found that higher levels of team identification led to a greater level of management cooperation, prosocial behavior, and performance tolerance in a professional sport team setting. It is possible that varying levels of identification with the sport of F-1 event could influence the outcomes in this study. Future studies should include theoretically relevant control variables such as team (or driver) identification. 
It should also be noted that the context of this study was an international recurring mega sport event. As a result, it is very likely that spectators attending the event have traveled from all over the world. It is also likely that the spectators who participated in this study were a mix of domestic residents, domestic tourists, and international tourists. While results showed that utilitarian and hedonic value perceptions positively influenced fan engagement behavior, utilitarian value was found to have a stronger influence than hedonic value on both management cooperation and prosocial behavior. When interpreting this finding, it is important to consider that domestic and international tourists may have placed a heavier emphasis on the utilitarian value associated with attending the event due to greater travel costs incurred. Future studies should take into consideration the residency type (e.g., resident, domestic tourist, and international tourist) and test for potential moderating effects.

\section{References}

Anderson, J. C., \& Gerbing, D. W. (1988). Structural equation modeling in practice: A review and recommended two-step approach. Psychological Bulletin, 103, 411-423.

Andersson, L. M., \& Bateman, T. S. (1997). Cynicism in the workplace: Some causes and effects. Journal of Organizational Behavior, 18, 449-469.

Auh, S., Bell, S. J., McLeod, C. S., \& Shih, E. (2007). Co-production and customer loyalty in financial services. Journal of Retailing, 83, 359-370.

Aulakh, P. S., \& Gencturk, E. F. (2000). International principalagent relationships: Control, governance and performance. Industrial Marketing Management, 29, 521-538.

Babin, B. J., Darden, W. R., \& Griffin, M. (1994). Work and/or fun: Measuring hedonic and utilitarian shopping value. Journal of Consumer Research, 20, 644-656.

Bagozzi, R. P., \& Yi, Y. (1988). On the evaluation of structural equation models. Journal of the Academy of Marketing Science, $16,74-94$.

BBC Sport. (2011, July 29). Turkish Grand Prix poised to lose 2012 F1 calendar spot. Retrieved from: http://www.bbc.co.uk/ sport/0/formula1/14348303

Bernthal, M. J., Koesters, T., Ballouli, K., \& Brown, M. T. (2015). Motivations and fan engagement related to professional bass fishing spectatorship. Sport Marketing Quarterly, 24, 6-18.

Bettencourt, L. A. (1997). Customer voluntary performance: Customers as partners in service delivery. Journal of Retailing, $73,383-406$.

Brady, M. K., \& Cronin, J. J., Jr. (2001). Some new thoughts on conceptualizing perceived service quality: A hierarchical approach. Journal of Marketing, 65(3), 34-49.

Brislin, R. W. (1970). Back-translation for cross-cultural research. Journal of Cross-Cultural Psychology, 3, 185-216.

Brodie, R. J., Hollebeek, L. D., Jurić, B., \& Ilić, A. (2011). Customer engagement: Conceptual domain, fundamental propositions, and implications for research. Journal of Service Research, 14, 252-271.

Byon, K. K., Zhang, J. J., \& Baker, T. A. (2013). Impact of core and peripheral service quality on consumption behavior of professional team sport spectators as mediated by perceived value. European Sport Management Quarterly, 13, 232-263.
Casey, M. (2013, April 10). Formula One remaines a tough sell in China. Associated Press. Retrieved from https://racing.ap.org/ article/formula-one-remains-tough-sell-china-0

Cronin, J. J., Jr., Brady, M. K., \& Hult, G. T. M. (2000). Assessing the effects of quality, value, and customer satisfaction on consumer behavioral intentions in service environments. Journal of Retailing, 76, 193-218.

Dholakia, U. M., Blazevic, V., Wiertz, C., \& Algesheimer, R. (2009). Communal service delivery: How customers benefit from participation in firm-hosted virtual P3 communities. Journal of Service Research, 12, 208-226.

Fornell, C., \& Larcker, D. F. (1981). Evaluating structural equation models with unobservable variables and measurement error. Journal of Marketing Research, 18, 39-50.

Gibbs, C., O'Reilly, N., \& Brunette, M. (2014). Professional team sport and Twitter: Gratifications sought and obtained by followers. International Journal of Sport Communication, 7 , $188-213$

Hair, J. F., Black, W. C., Babin, B. J., \& Anderson, R. E. (2010). Multivariate data analysis. Upper Saddle River, NJ: Pearson Prentice Hall.

Hill, B., \& Green, B. C. (2000). Repeat attendance as a function of involvement, loyalty, and the sportscape across three football contexts. Sport Management Review, 3, 145-162.

Huang, H., Mao, L. L., Kim, S. K., \& Zhang, J. J. (2014). Assessing the economic impacts of three major sport events in China: The perspective of attendees. Tourism Economics, 20, 1277-1296.

Jensen, J. A., Cobbs, J., Grozo, M. D. (2014). The nich portfolio strategy to global expansion: The influence of market resources on demand for Formula One Racing. Journal of Global Marketing, 27, 247-261.

Johnson, D. (2016, April 16). Declining audiences and a complete lack of interest-How much longer can the Chinese Grand Prix go on? The Telegraph. Retrieved from http://www. telegraph.co.uk/formula-1/2016/04/16/declining-audiencesand-a-complete-lack-of-interest--how-much-1/

Kline, R. B. (2010). Principles and practice of structural equation modeling (3rd ed.). New York, NY: The Guilford Press.

Kumar, V., Aksoy, L., Donkers, B., Venkatesan, R., Wiesel, T., \& Tillmanns, S. (2010). Undervalued or overvalued customers: Capturing total customer engagement value. Journal of Service Research, 13, 297-310.

Ma, J., Huang, X., \& Huang, H. (2011). F1 Chinese Grand Prix and the urban tourism development in Shanghai. Sports Science Research, 32, 22-27.

Mallinckrodt, B., Abraham, W. T., Meifen, W., \& Russell, D. W. (2006). Advances in testing the statistical significance of mediation effects. Journal of Counseling Psychology, 53, 372-378.

McDonald, H., \& Karg, A. J. (2014). Managing co-creation in professional sports: The antecedents and consequences of ritualized spectator behavior. Sport Management Review, 17, 292-309.

Petrick, J. F. (2002). Development of a multi-dimensional scale for measuring the perceived value of a service. Journal of Leisure Research, 34, 119-134.

Podsakoff, P. M., MacKenzie, S. B., Lee, J.-Y., \& Podsakoff, N. P. (2003). Common method biases in behavioral research: A critical review of the literature and recommended remedies. Journal of Applied Psychology, 88, 879-903.

Swanson, S. R., Gwinner, K., Larson, B. V., \& Janda, S. (2003). Motivations of college student game attendance and wordof-mouth behavior: The impact of gender differences. Sport Marketing Quarterly, 12, 151-162. 
Sweeney, J. C., \& Soutar, G. N. (2001). Consumer perceived value: The development of a multiple item scale. Journal of Retailing, 77, 203-220.

Sylt, C., \& Reid, C. (2011). Formula One's financial performance guide. London, UK: Communications and Network Consulting.

van Doorn, J., Lemon, K. N., Mittal, V., Nass, S., Pick, D., Pirner, P., \& Verhoef, P. C. (2010). Customer engagement behavior: Theoretical foundations and research directions. Journal of Service Research, 13, 253-266.

Verhoef, P. C., Reinartz, W. J., \& Krafft, M. (2010). Customer engagement as a new perspective in customer management. Journal of Service Research, 13, 247-252.

Wakefield, K. L., Blodgett, J. G., \& Sloan, H. J. (1996). Measurement and management of the sportscape. Journal of Sport Management, 10, 15-31.

Watkins, B., \& Lewis, R. (2014). Winning with apps: A case study of the current branding strategies employed on professional sport teams' mobile apps. International Journal of Sport Communication, 7, 399-416.

Westerbeek, H. M., \& Shilbury, D. (2003). A conceptual model for sport services marketing research: Integrating quality, value and satisfaction. International Journal of Sports Marketing \& Sponsorship, 5, 11-31.

Yoshida, M., Gordon, B., Nakazawa, M., \& Biscaia, R. (2014). Conceptualization and measurement of fan engagement: Empirical evidence from a professional sport context. Journal of Sport Management, 28, 399-417.

Yoshida, M., James, J. D., \& Cronin, J. J., Jr. (2013). Value creation: Assessing the relationships between quality, consumption value and behavioural intentions at sporting events. International Journal of Sports Marketing \& Sponsorship, 14, 126-148. 


\section{Appendix. Measurement Items}

\begin{tabular}{|c|c|c|c|c|}
\hline Variables & M & SD & Skewness & Kurtosis \\
\hline 1. Ticket takers were very courteous at the Shanghai F-1 event (ISQ1) & 5.60 & 1.27 & -1.05 & 1.02 \\
\hline 2. Security officers were very courteous at the Shanghai F-1 event (ISQ2) & 5.60 & 1.24 & -1.05 & 1.16 \\
\hline 3. Ushers were very courteous at the Shanghai F-1 event (ISQ 3) & 5.66 & 1.20 & -1.12 & 1.47 \\
\hline 4. Restaurant servers were very courteous at the Shanghai F-1 event (ISQ 4) & 5.57 & 1.18 & -.80 & .50 \\
\hline 5. Ticket personnel was very friendly at the Shanghai F-1 event (ISQ5) & 5.75 & 1.13 & -.95 & .79 \\
\hline 6. Employees at the Shanghai F-1 event were very professional (ISQ6) & 5.73 & 1.13 & -.96 & 1.14 \\
\hline 7. Signs at this venue give clear directions of where things are located (PEQ1) & 5.57 & 1.31 & -1.11 & 1.03 \\
\hline 8. This is a nice-looking venue (PEQ2) & 5.52 & 1.23 & -.82 & 60 \\
\hline 9. This venue provides comfortable seats (PEQ3) & 5.12 & 1.37 & -.67 & .25 \\
\hline 10. This venue layout makes it easy to get to your seat (PEQ4) & 5.46 & 1.21 & -1.04 & 1.45 \\
\hline 11. This venue has high quality scoreboards (PEQ5) & 5.30 & 1.40 & -.75 & .21 \\
\hline 12. The concessions in this venue provide quality food (PEQ6) & 4.85 & 1.50 & -.48 & -.27 \\
\hline 13. Shanghai F-1 event experience was reasonably priced (UPV1) & 5.12 & 1.39 & -.65 & .05 \\
\hline 14. Shanghai F-1 event experience was good value for money (UPV2) & 5.25 & 1.30 & -.72 & .30 \\
\hline 15. Shanghai F-1 event experience was worth the money (UPV3) & 5.46 & 1.30 & -.91 & .77 \\
\hline 16. At the F-1 event I feel happy (HPV1) & 5.74 & 1.30 & -1.44 & 2.45 \\
\hline 17. At the F-1 event I feel energetic (HPV2) & 5.69 & 1.26 & -1.24 & 1.89 \\
\hline 18. At the F-1 event I feel excited (HPV3) & 5.82 & 1.24 & -1.41 & 2.40 \\
\hline 19. At the F-1 event I feel thrilled (HPV4) & 5.76 & 1.27 & -1.25 & 1.84 \\
\hline 20. I try to work cooperatively with this event (Formula One) (MGC1) & 5.62 & 1.41 & -1.15 & 1.01 \\
\hline 21. I do things to make Formula One event management easier (MGM2) & 5.54 & 1.37 & -.94 & .43 \\
\hline 22. The employees of Formula One get my full cooperation (MGC3) & 5.71 & 1.29 & -1.10 & 1.06 \\
\hline 23. I often interact with other fans to talk about issues related to Formula One (PSB1) & 5.39 & 1.44 & -.90 & .52 \\
\hline 24. I often advise other fans on how to follow Formula One (PSB2) & 5.08 & 1.54 & -.67 & -.08 \\
\hline $\begin{array}{l}\text { 25. I spend time on social media (e.g., Facebook, Twitter) sharing information with } \\
\text { other fans of Formula One (PSB3) }\end{array}$ & 5.13 & 1.73 & -.84 & -.09 \\
\hline
\end{tabular}

Note. ISQ = interaction service quality; $\mathrm{PEQ}=$ physical environment quality; $\mathrm{UPV}=$ utilitarian perceived value; $\mathrm{HPV}=$ hedonic perceived value; $\mathrm{MGC}=$ management cooperation; $\mathrm{PSB}=$ prosocial behavior. 
Copyright of Sport Marketing Quarterly is the property of Fitness Information Technology, Inc. and its content may not be copied or emailed to multiple sites or posted to a listserv without the copyright holder's express written permission. However, users may print, download, or email articles for individual use. 